\title{
NEGOCIACIONES DE LA MASCULINIDAD EN EL HEAVY ESPAÑOL DE LOS OCHENTA
}

\section{NEGOTIATIONS OF MASCULINITY IN SPANISH EIGHTIES HEAVY METAL}

Author / Autora:

Sara Arenillas Meléndez

Universidad Internacional de La Rioja

Logroño, Spain

sara.arenillas@unir.net

https://orcid.org/0000-0002-4613-3816

Submitted / Recibido: 21/06/2020

Accepted / Aceptado: 26/10/2020

To cite this article / Para citar este artículo: Arenillas Meléndez, S. (2021). Negociaciones de la masculinidad en el heavy español de los ochenta Feminismo/s, 38, 261-279. https://

doi.org/10.14198/fem.2021.38.10

Licence / Licencia:

This work is licensed under a Creative Commons Attribution 4.0 International.

\section{(c) (1)}

(C) Sara Arenillas Meléndez

\section{Sara ARENILLAS MELÉNDEZ}

\section{Resumen}

El heavy surgió en España a principios de los ochenta con bandas como Barón Rojo, que tenían influencia de la NWOBHM y se ajustaban a la articulación de lo que Deena Weinstein denomina como «masculinidad cultural» del heavy. A mediados de esta década aparecieron propuestas como la de Sangre Azul, que recogían el trabajo de grupos norteamericanos del glam y el lite metal. Éstos proponían un discurso más abierto en términos de género, que favorecía la implicación de mujeres dentro de la escena heavy. Este artículo trata de analizar las propuestas presentes en el heavy español de los ochenta a través del caso de Barón Rojo y Sangre Azul. Mediante una metodología interdisciplinar, se estudia cómo el primero articulaba una masculinidad más cercana al tipo de la masculinidad hegemónica, mientras que el segundo, a través de estrategias como la inclusión del romanticismo en las letras, se desviaba de ella.

Palabras clave: heavy; música popular urbana; masculinidades; NWOBHM; glam metal. 


\begin{abstract}
Heavy metal arose in Spain in the early eighties with bands such as Barón Rojo, which were influenced by NWOBHM. Barón Rojo suited the features of what Deena Weinstein has labeled as heavy metal's «cultural masculinity». In the middle eighties, bands such as Sangre Azul, widely influenced by North American groups of glam and lite metal, gained success. Sangre Azul displayed a flexible discourse in terms of gender, which enabled the commitment of women with heavy metal. This research aims to analyse gender negotiations that were carried out within the Spanish eighties heavy metal scenes. Following an interdisciplinary method, it is studied how hegemonic masculinity is articulated in the case of Barón Rojo. At the same time, it is analysed how Sangre Azul blurred the limits of heteronormative masculinity by making romantic lyrics or using harmonies closer to pop music.
\end{abstract}

Keywords: Heavy; Spanish popular music; Masculinities; NWOBHM; Glam metal.

\title{
1. EL HEAVY Y LA MASCULINIDAD. EL CASO ESPAÑOL
}

El heavy ha sido una de las manifestaciones más analizadas desde el punto de vista de género dentro de los estudios de músicas populares urbanas. En las últimas décadas se ha realizado un número importante de trabajos que abordan el heavy desde la perspectiva de género (Heesch \& Scott, 2019), atendiendo a cuestiones de tipo subcultural (Nordström \& Herz, 2013; Rogers, 2015), musical (Heesch, 2019; Moore, 2011) e incluso desde la perspectiva queer (Clifford-Napoleone, 2015).

En 1993 Robert Walser fue pionero en estos estudios con la publicación Running with the devil: power, gender and madness in heavy metal music, donde analizaba el discurso de género en el heavy en el capítulo «Forging masculinity: heavy metal sounds and images of gender» (1993, pp. 108-136). Walser subraya que el metal está «abrumadoramente preocupado por presentar imágenes y confrontar ansiedades que tradicionalmente se han entendido como propias de los hombres» a través de manifestaciones y medios musicales que «se han codificado convencionalmente como masculinos» (1993, p. 110) ${ }^{1}$. El heavy presenta «fantasías de virtuosismo y control masculino»

1. «But metal is overwhelmingly concerned with presenting images and confronting anxieties that have been traditionally understood as peculiar to men, through musical means that have been conventionally coded as masculine» (Walser, 1993, p. 110).

Feminismo/s 38, July 2021, 261-279 
que, musicalmente, se articulan a través de una dialéctica entre el poder y la libertad. Esta experiencia es construida a través de tesituras vocales extremas, «acordes de poder» (power chords), la inclusión de la distorsión y un volumen alto, gracias al uso de amplificadores (Walser, 1993, pp. 108-109).

Por su parte, Deena Weinstein en «The empowering masculinity of British heavy metal», capítulo incluido en Heavy metal music in Britain, describe cómo el heavy articula una masculinidad esencialista centrada en las características físicas de los hombres (fuerza, potencia sexual, resistencia física, etc.). Esta masculinidad, atendiendo a los estudios de autores como Connell, estaría cercana a la «masculinidad hegemónica» (Connell, 1995; Johnson, 2014, pp. 3-8; Weinstein, 2009, p. 19). Deena Weinstein matiza que el heavy pondría de manifiesto lo que ella llama «masculinidad cultural», que estaría constituida por «características clave de la masculinidad biológica y social», pero crecería y fluiría libremente fuera de sus grupos biológicos y sociales de origen. Así, esta «masculinidad cultural» habría permitido y permitiría en la actualidad el disfrute y la identificación de las mujeres con el heavy (Weinstein, 2009, p. 19). Esto puede observarse, sobre todo, a partir de la segunda mitad de los ochenta, cuando el heavy comenzó a tener una audiencia más equilibrada en términos de género gracias a las propuestas del glam/ hair metal y el metal «ligero» o lite metal (Walser, 1993, pp. 110-111). En este momento surgió también la corriente del thrash metal, que redundaba en la retórica de poder y masculinidad del heavy. Se creó, así, una escisión dentro del heavy, entre el glam y el lite metal, y subgéneros como el thrash metal, que tenía importantes connotaciones de género (Weinstein, 2000, pp. 45-57 ${ }^{2}$. Esta división es un ejemplo de cómo la ansiedad que genera la propia masculinidad ha dado lugar a constantes negociaciones del género dentro del heavy (Walser, 1993, p. 110).

El objetivo principal de este artículo es analizar cómo estos procesos de negociación se produjeron también en el heavy español de los ochenta, tomando como muestra representativa los casos de Barón Rojo y Sangre Azul.

2. En este sentido, Sarha Moore ha apuntado recientemente cómo la vertiente del thrash metal utilizaba con mayor profusión ciertas disonancias (la supertónica descendida), que, según ella, están ligadas a la articulación de la masculinidad en el heavy (2011, pp. 7-8). 
El heavy en España ha sido estudiado desde la musicología con trabajos como «Héroes frigios, nación y distorsión. La batalla por la supertónica descendida como signo musical en el metal español» (García-Peinazo, 2019), Espíritus rebeldes: el heavy metal en España (Galicia Poblet, 2005) o «Monstruos y fronteras en el heavy: un análisis desde lo híbrido»(Martínez García, 2005). También desde la sociología (del Val, 2017), así como ampliamente reseñado desde el periodismo y la divulgación (Domínguez, 2004; López Martínez, 2009). Asimismo, el heavy español ha sido analizado desde una perspectiva de género desde la academia, -por ejemplo, en «Decibelios y testosterona: una aproximación a las imágenes de género del rock y el heavy» (Martínez García, 2003)- y el periodismo (Allué Montilla, 2017). El heavy se desarrolla en Madrid a principios de los ochenta, al mismo tiempo que la movida madrileña, de la mano de bandas como Barón Rojo y Obús. Éstas se convirtieron en una referencia para el heavy nacional. Barón Rojo y sus compañeros de escena eran la adaptación española de la NWOBHM (New Wave of British Heavy Metal), que estaba en auge en Reino Unido a principios de los ochenta con formaciones como Iron Maiden.

Fernán del Val, recogiendo a Walser, señala que «una de las características del heavy es la sobredimensión de la masculinidad», considerando que «en el caso español [...] se da también una situación de homosocialidad de la escena, basada en un entendimiento implícito y explícito, en las letras y en los patrones de identificación, de que todos (músicos, audiencias, periodistas) eran varones heterosexuales» (2017, p. 516). En torno a 1985 aparecieron bandas como Bella Bestia y Sangre Azul que tenían influencia del glam metal norteamericano. Silvia Martínez García apunta que la mayoría de los grupos de heavy españoles construían un discurso basado en la hipermasculinidad, siendo infrecuente que adoptaran la transgresión de género del glam americano (2003, pp. 111-113). De esta forma, el caso de Bella Bestia y Sangre Azul podría considerarse una «anomalía» dentro de la escena española. Sin embargo, Sangre Azul fue uno de los grupos de heavy que más éxito tuvo durante la segunda mitad de los ochenta, por lo que es importante el estudio de su propuesta y, especialmente, desde la perspectiva de género.

En este artículo se analiza cómo Barón Rojo articulaba una masculinidad convencional y esencialista que, siguiendo a Walser y Weinstein, definiría a gran parte del heavy, mientras que Sangre Azul se alejaba de ella. La 
metodología que se ha seguido en este estudio ha sido interdisciplinar y ha atendido principalmente al análisis del discurso musical, aunque también se tiene en cuenta puntualmente la iconografía y los textos de las piezas. Las canciones que se han elegido para comparar ambas bandas son «Resistiré», incluida en uno de los discos de mayor éxito de Barón Rojo, Volumen Brutal (1982), y «Mil y una noches», del segundo álbum de Sangre Azul, Cuerpo a cuerpo (1988). «Resistiré» se ha escogido, además de por ser uno de los temas más conocidos del grupo, como ejemplo de uso de la armonía típica del heavy. Además, la temática de esta pieza encaja con lo que Weinstein y Walser señalan con respecto a la construcción de la masculinidad en el heavy. «Mil y una noches» se utilizó por ser una de las canciones de Sangre Azul que versan de forma más evidente sobre el amor romántico, y por tener una armonía y unas estrategias musicales interesantes que dan pie a la reflexión en torno a las cuestiones de género que aquí se plantean. Estos ejemplos permiten comparar de manera concisa el discurso propuesto por ambas formaciones, y el cambio que suponía en términos de género la aparición de grupos como Sangre Azul dentro de la escena española.

\section{EL VOLUMEN BRUTAL DE BARÓN ROJO}

Barón Rojo fue, de los grupos surgidos a principios de los ochenta, uno de los más destacados y que mayor influencia tuvo en el heavy español de las siguientes décadas. Galicia Poblet señala que «fue el primer grupo de heavy que hubo en España» y que junto con Obús «fueron los adalides del heavy metal español» (2005, p. 71). Barón Rojo fue fundado en 1980 por los hermanos Armando y Carlos de Castro (guitarras), José Luis Campuzano «Sherpa» (voz y bajo) y Hermes Calabria (batería). Esta plantilla perduró hasta 1990, momento a partir del cual el grupo sufrió diferentes cambios, pero manteniéndose siempre los hermanos de Castro como núcleo central de la formación. El primer disco de Barón Rojo se tituló Larga vida al rock E roll (1981), fue editado por el sello Chapa y producido por el locutor Vicente Romero (conocido como Vicente «Mariscal» Romero). Barón Rojo viajó ese año a Inglaterra y conoció a músicos como Bruce Dickinson, de Iron Maiden, o Ian Gillan, de Deep Purle, quien le dispone sus Kingsway

Feminismo/s 38, July 2021, 261-279 
Studios para la grabación del segundo disco (del Val, 2017, p. 346; Galicia Poblet, 2005, p. 72).

El segundo trabajo de Barón Rojo se tituló Volumen Brutal, fue editado en 1982 y es considerado uno de los álbumes de referencia del heavy español ${ }^{3}$. Volumen brutal logró ser disco de platino y fue distribuido en Europa con el sello Kamaflage. Barón Rojo logró, además, actuar el año de su lanzamiento en el Reading Festival en Reino Unido, junto a grupos destacados de la NWOBHM como Iron Maiden (del Val, 2017, p. 346; Galicia Poblet, 2005, p. 73). Después, la banda continuó su ascenso con trabajos como Metalmorfosis (1983), el disco en directo Barón al rojo vivo (1984), y En un lugar de la marcha (1985). Ésta fue la época de mayor esplendor del grupo. Posteriormente siguió lanzando discos, continuando hoy en día en activo y manteniéndose como una referencia del heavy español ${ }^{4}$.

Barón Rojo responde a las características que Deena Weinstein describe como articuladoras de la «masculinidad cultural» del heavy. Así, el propio nombre de la banda hace referencia al piloto de cazas alemán de la Primera Guerra Mundial, Manfred Albrecht Freiherr von Richthofen. Éste era conocido con el apodo de El Barón Rojo por su origen aristocrático y por el color rojo con el que pintó su avión de guerra. La figura de El Barón Rojo se relaciona, por tanto, con el icono del «guerrero» que Weinstein menciona como uno de los más usados en el heavy, y que pone en relación con su representación de la masculinidad $\left(2009\right.$, p. 26) ${ }^{5}$. Otros símbolos que menciona Weinstein son el del diablo y el mal (2009, p. 26). Barón Rojo también recoge estos en canciones de Volumen Brutal como «Los roqueros van al infierno», «Satánico plan (Volumen brutal)» y «Las flores del mal». Además, hay una velada alusión a la conexión del grupo con la escena inglesa en «El Barón vuela sobre Inglaterra».

3. Galicia Poblet señala que es «pieza fundamental de la historia del heavy español» (2005, p. 72) y del Val que «Volumen brutal es considerado el mejor trabajo de Barón Rojo» (2017, p. 346).

4. Por ejemplo, en uno de los conciertos que celebró la banda americana Metallica en febrero de 2018 en Madrid esta realizó una versión del popular tema de Barón Rojo «Los roqueros van al infierno» (Lerena, 2018).

5. Uno de los casos más claros de la utilización de esta figura sería la del grupo norteamericano Manowar, que tomó su nombre de la conjunción entre «war», «guerra», y la abreviación de «mannish», «varonil». 
A diferencia del heavy extranjero, Barón Rojo presentaba textos que parecían contener cierta denuncia social, una particularidad que compartía con otros grupos del rock urbano y el heavy español, y que se achaca habitualmente a la situación política del país en aquella época (del Val, 2017, pp. 482-483; Galicia Poblet, 2005, pp. 69-70)6. Canciones de Volumen brutal como «Resistiré», con las frases «yo maldigo vuestro crimen/ sé que lo tendréis que pagar/y no os servirá el dinero/ para remediar tanto mal», o «Son como hormigas», que señala «cuando el gobierno te manda una carta/ has de temblar, / señor ciudadano/ tiene que pagar un poco más», pueden dar pie a imaginar una inclinación política ligada a la protesta social desde la clase obrera ${ }^{7}$. La particularidad de estos textos reside en que, aunque las alusiones a la política no estaban totalmente fuera de la $\mathrm{NWOBHM}^{8}$, los grupos anglosajones centraban sus líricas en alusiones a monstruos y fantasías diabólicas (caso del tema «The number of the beast» de Iron Maiden), y no eran habituales los atisbos de protesta o denuncia social explícita. Sin embargo, la posición de disidencia política podría encajar bien con la figura del «proscrito»o «fuera de la ley» que Weinstein incluye en su lista de iconos usados por el heavy para la articulación de la masculinidad (2009, p. 26), aunque también es importante tener en cuenta la influencia del punk en esta época.

Musicalmente, Barón Rojo responde a los esquemas propios del heavy de este período. Walser, en el ya mencionado Running with the devil: power, gender, and madness in heavy metal music explica que la mayoría del heavy está construido sobre los modos musicales eólico y dórico ${ }^{9}$, así como también

6. España en los ochenta estaba acabando de culminar su período de Transición, después de haber sufrido una dictadura durante cuarenta años. Por ello, Fernán del Val señala que «a diferencia de los grupos británicos o norteamericanos de heavy metal, algunos grupos de heavy metal españoles mostraron en sus letras una actitud denunciatoria» (2017, pp. 482-483).

7. El caso de Barón Rojo es especialmente interesante porque los hermanos de Castro habían ingresado en el PCE (Partido Comunista de España) en 1974, y actuaron en conciertos organizados por este partido en 1984 (del Val, 2017, p. 489; Galicia Poblet, 2005, p. 73).

8. Es conocida la censura de que fue objeto Iron Maiden por incluir un dibujo de Margaret Thatcher asesinada en la portada de Sanctuary, de 1980.

9. Los modos a los que alude Walser son los procedentes de la música medieval, y no de la teoría musical griega. Así, el modo eólico sería el derivado de la escala de La y el modo dórico de la de Re (1993, p. 46). 
serían frecuentes en él la utilización de disonancias heredadas del blues ${ }^{10}$. Igualmente, señala que es habitual en el heavy el uso de los grados VIIb y VIb, y especialmente enlazados en la progresión VIb-VIIb-I derivada del modo eólico. Esta progresión es lo que Andrew Cope denomina «tricordio eólico» y que, unida a la construcción de los acordes como power chords, generaría una atmósfera sonora oscura y opresiva (2010, pp. 118-119) ${ }^{11}$.

Los power chords o "acordes de poder» son una de las piezas centrales con las que el heavy construye su discurso de poder. Son acordes sin tercera y ejecutados en las cuerdas graves de la guitarra, a menudo utilizando la sexta y quinta cuerda al aire, lo que produce frecuencias extremadamente densas. Así, los power chords producen potentes señales que, al ser amplificadas y con el añadido de la distorsión, generan una vibración espesa y apabullante que articularía a nivel musical el discurso de poder y masculinidad del heavy. Como señala Walser, estas estrategias median entre el poder que representa la música, y la experiencia de poder del oyente. Así, el «volumen extremo» del heavy es percibido como el más poderoso de los discursos musicales (Walser, 1993, pp. 42-45).

Barón Rojo hace uso de estos esquemas sonoros procedentes del heavy anglosajón. Su conocido tema «Resistiré», contenido, como señalamos, en Volumen brutal, es un buen ejemplo del uso del modo eólico y el tricordio VIb-VIIb-I en el heavy. La canción utiliza el modo eólico de Fa\#, y las estrofas están construidas alrededor del I (Fa\#). El puente que enlaza al estribillo

10. Walser alude al famoso riff del conocido tema de Deep Purple «Smoke on the wáter» (Sol-Sib- Do; Sol-Sib-Reb-Do) que introduce una 5. ${ }^{a}$ disminuida (entre el Sol y el Reb) propia del blues, combinada con el uso del modo eólico en Sol (1993, p. 47).

11. El modo eólico sería el derivado de la escala de La, que produce la tonalidad de La menor, pero sin la inclusión de la sensible (el Sol\#). La progresión i-VIIb-VIb- en La menor correspondería a la secuencia de acordes de La m - Sol - Fa (Walser, 1993, p. 47): ésta es la que aparecería, por ejemplo, al final del conocido tema de Led Zeppelin «Stairway to heaven». Sin embargo, como apunta Andrew Cope en su estudio Black Sabbath and the rise of heavy metal music, es Black Sabbath el que comienza a usar esta estructura utilizando power chords en la canción «Paranoid». El uso del tricordio eólico junto a power chords generaría una «naturaleza lastimera» y una indefinición sonora que encajaría bien con el contenido de locura y paranoia de la canción, y cuya atmósfera oscura copiaron generaciones posteriores. En este sentido, Cope analiza cómo Iron Maiden utilizaba este recurso poniendo como ejemplo su conocido tema «The trooper» (2010, pp. 118-120).

Feminismo/s 38, July 2021, 261-279 
se articula sobre el VIIb (Mi). El estribillo cierra sus frases sobre el tricordio eólico en Fa\# utilizando power chords (Re5-Mi5-Fa\#5). De esta forma, la música enfatiza y amplifica la fuerza de las palabras finales, «resistiré hasta el fin». El tricordio eólico aparece en otras canciones estandarte de Barón Rojo de Volumen brutal como «Los roqueros van al infierno», cuyos versos iniciales están en su mayor parte construidos sobre esta estructura en el modo de Sol (Mib5-Fa5-Sol m). Asimismo, el propio nombre de este segundo disco de Barón Rojo alude a la potencia sonora del heavy: al Volumen brutal de su «golpe» sonoro. Este significado se ve reforzado por la portada del álbum: en ella aparece el dibujo de una mano apretando una pulsera de tachuelas a modo de puño americano que rompe ficticiamente la portada de cartón (véase Ilustración 1).

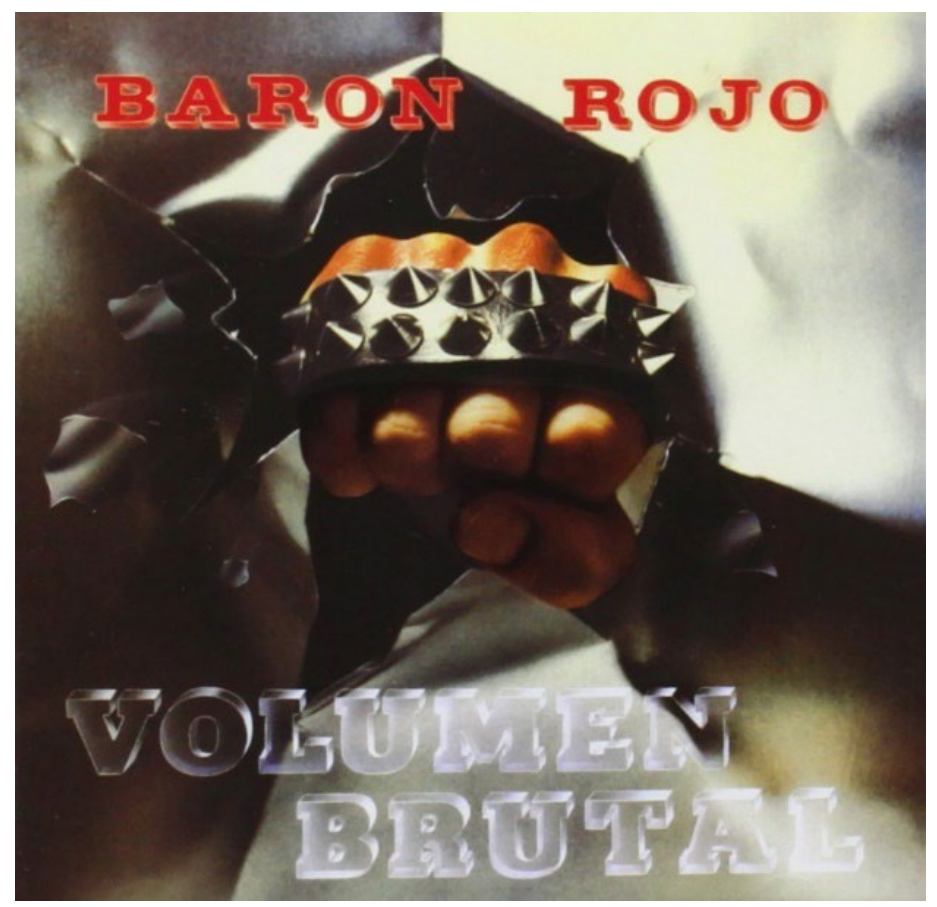

Ilustración 1. Portada del segundo disco, Volumen brutal, de Barón Rojo, donde se puede ver un puño con una pulsera de tachuelas que golpea y «rompe» la cubierta. 
Así, este ejemplo de Barón Rojo ilustra bien cómo el heavy español seguía y emulaba las estrategias sonoras, visuales y discursivas del heavy anglosajón de articulación del poder y la masculinidad.

\section{LA MASCULINIDAD «ROMÁNTICA»DE SANGRE AZUL.}

Fernán del Val recoge a Weinstein y Walser para señalar el giro que la escena heavy dio a mediados de los ochenta en cuanto al género. Éste, como se ha mencionado, fue posible gracias a trabajos que se enmarcaban dentro del glam y el lite metal como el de Bon Jovi. Bon Jovi conjugaba la autenticidad del sonido roquero con la sinceridad del «romanticismo pop», lo que permitía que un mayor número de oyentes femeninas se sintieran identificadas con su propuesta (Walser, 1993, pp. 120-124). Del Val menciona a Sangre Azul como ejemplo de adaptación del discurso de Bon Jovi al heavy español, y puntualiza que este tipo de iniciativas no fueron bien recibidas por «una parte de la escena heavy al entender que eran excesivamente comerciales» (2017, p. 516).

Sangre Azul se formó a mediados de los ochenta en Madrid, en una época en la que, según Galicia Poblet, comenzaba el declive del heavy metal nacional (2005, p. 116). La primera plantilla de Sangre Azul estaba compuesta por José Castañosa (voz), Carlos Raya y Juan Antonio Martín (guitarras), Julio Díaz (bajo) y Luis Santurde (batería). El grupo produjo un primer trabajo en 1985 con cinco temas gracias a haber ganado un concurso de rock. Después, José Castañosa abandona la formación para ser sustituido por Tony Villalba, conocido más tarde como Tony Sölo. Sangre Azul firma entonces un contrato con Hispavox que dará lugar a la grabación de tres álbumes: Obsesión (1987), Cuerpo a cuerpo (1988) y El silencio de la noche (1989). Después de realizar varias giras por España y el extranjero, el grupo se separó en 1992 y algunos de sus componentes siguieron en primera línea del panorama musical español (Galicia Poblet, 2005, pp. 116-118) ${ }^{12}$.

12. Por ejemplo, Carlos Raya se incorporó como guitarrista de M-Clan a principios de los 2000, y colaboró con artistas como Antonio Vega o Fito. 
Sangre Azul logró vender un número considerable de copias de sus trabajos $^{13}$ y a menudo se ha señalado la mayor presencia de mujeres entre su audiencia ${ }^{14}$. Además de la asociación con Bon Jovi que apunta del Val, el estilo de Sangre Azul ha sido calificado como AOR y relacionado con Whitesnake y Van Halen. Si bien, Sangre Azul tenía también influencias del glam americano de grupos como Dokken (Galicia Poblet, 2005, pp. 116-117; «Sangre Azul», 2005) $)^{15}$.

Fernán del Val señala que la novedad que aportó Sangre Azul a la escena del heavy nacional estaba «básicamente en las letras». Éstas redundan sobre el mito del amor romántico y la vulnerabilidad masculina, pero «manteniendo los cánones sonoros que caracterizan al heavy» (del Val, 2017, p. 516). Temas como «Cien años de amor», «Todo mi mundo eres tú» y «Mil y una noches» muestran este cambio de forma clara. Los textos de estas canciones no sólo tienen una temática amorosa, sino que utilizan pronombres en segunda persona como «tú» o «contigo» que afianzan la identificación del oyente anónimo con el otro al que se dirige el afecto amoroso. Ejemplos de esta estrategia son: la frase "Contigo viviré/ mil y una noches», que da título al tema «Mil y una noches» y que se repite en su estribillo; la segunda estrofa de «Todo mi mundo eres tú», que señala «sólo estando junto a ti/ nada importa ya/ todo es distinto si estás tú»; y el puente de «Cien años de amor», que indica «mírame, siénteme, estoy aquí junto a ti/ [...]/ yo te prometo cien años de amor». Esta maniobra era particularmente disruptiva no sólo por tratar el tema del amor ${ }^{16}$, sino también por la ansiedad que podía generar

13. Tony Villalba en la entrevista realizada para el programa Rockcinante señala que por aquel entonces Sangre Azul vendía aproximadamente 30.000 o 40.000 copias de cada uno de sus álbumes (Sangre Azul, 2011).

14. En el número 45 de la revista Heavy rock, publicado en mayo de 1987, se señalaba que «las chicas se acercan en número apreciable en relación con lo poco que se las suele ver en conciertos de rock fuerte a los shows de Sangre Azul» (Giner, 1987).

15. El propio Tony Villalba señala en una breve entrevista que le realizaron a raíz de la participación de Sangre Azul en el programa A tope en 1988 que la banda tenía como referencia a grupos como Dokken, Bon Jovi y Whitesnake. De hecho, en la conocida página Discogs se etiqueta a Sangre Azul doblemente como glam metal y como AOR (Sangre Azul, 1988; Sangre Azul, n.d.).

16. Deena Weinstein cita las declaraciones del líder de Iron Maiden Steve Harris, quien decía que hablar de romance en las canciones le parecía «debilucho» (wimpy), para señalar que el heavy no solía tener textos sobre el amor (2009, p. 25).

Feminismo/s 38, July 2021, 261-279 
esta direccionalidad en la audiencia masculina. La enmarcación clara del receptor en un contexto de amor romántico hacía difícil que sus seguidores pudiesen relacionar el sentido de las letras con la fraternidad masculina y la homosocialidad que forjaba el sentimiento de comunidad del heavy. Sin embargo, estas letras facilitaban la identificación de las mujeres con el sujeto al que iban dirigidas.

Los textos de Sangre Azul se alejan, asimismo, de la denuncia social que había caracterizado a la primera oleada del heavy español, lo que aumentaba la suspicacia hacia ellos. Como apuntamos, gran parte de los fans y la crítica especializada del heavy vertían con frecuencia acusaciones de comercialidad sobre la banda (del Val, 2017, p. 484) ${ }^{17}$. Sin embargo, cabe señalar que Sangre Azul tenía canciones que redundaban sobre el propio rock, lo que del Val denomina «habitus roquero» ${ }^{18}$ («Sólo rock \& roll», «A golpes de rock»), el espacio urbano ( El rey de la ciudad», «Invadiendo tu ciudad») y aspectos de la «masculinidad cultural» que rodea al heavy («Velocidad», «Abre fuego», «Sediento de sangre», etc.). Esto demuestra que la banda trataba de ajustarse y mantener los lazos con el canon del heavy, lo que generaba contradicción si se oponía al romanticismo de los otros temas.

El discurso de Sangre Azul también era diferente al de grupos como Barón Rojo en lo que respecta a la música. Robert Walser señala que los modos mixolidio y jónico, relacionados con el modo mayor en la armonía tonal, son habituales del pop (1993, p. 46). Tanto Bon Jovi como grupos de glam metal combinaban estos modos con estructuras sonoras más propias del

17. Las acusaciones de comercialidad fueron una constante en las críticas al grupo por parte de la prensa especializada del heavy y es posible que influyeran en la decisión de disolver el grupo. Por ejemplo, en una entrevista en Metal Hammer se preguntaba a la banda por el hecho de que «los heavies más duros» les hubieran criticado «en ocasiones» por ser «excesivamente comerciales», a lo que el cantante Tony Villalba se defendía señalando: «No estoy nada de acuerdo en que las canciones sean comerciales, somos una banda de rock al cien por cien, hay temas que suenan menos duros quizás por la melodía o los coros, pero luego en directo somos un grupo totalmente duro» (Singla, 1988, p. 21).

18. Fernán del Val considera que los textos de los grupos de heavy españoles encajaban en siete categorías: 1) la idea de comunidad; 2) críticas a lo comercial; 3) el rock como resistencia; 4) el «habitus roquero»; 5) el espacio urbano; 6) pacifismo y utopía; y 7) hedonismo, sexo y ocio. Del Val menciona a Sangre Azul al desarrollar la última (2017, pp. 490-518).

Feminismo/s 38, July 2021, 261-279 
heavy (tricordio eólico, power chords, etc.) (Walser, 1993, pp. 122, 127). Esto jugaba un importante papel en la proyección de un discurso de género más abierto, al combinar la sonoridad mayor y más tonal del pop con estrategias musicales del heavy que connotaban fuerza y potencia.

Sangre Azul seguían esta última línea. Un ejemplo claro sería el tema «Mil y una noches». La canción se inicia con la descripción de la inclinación amorosa del narrador por el sujeto al que va dirigida. El texto comienza diciendo «la magia de la noche/ su trampa me tendió/ y entre la multitud/ solos tú y yo», y la cuarta estrofa señala «y pierdo el control/ de mis sentidos/ y mi obsesión/ es tenerte conmigo».

Musicalmente «Mil y una noches» está construida sobre el tricordio eólico de Si (Do\#-La-Si) que se enuncia en el riff de la introducción. Este riff es sobre el que están articulados los estribillos y acompaña la declaración de compromiso romántico del narrador, «contigo viviré/ mil y una noches». Los acordes de este riff están ejecutados en posiciones que utilizan las cuerdas graves de la guitarra, generando la característica sonoridad potente del heavy. Sin embargo, el efecto «menor» y modal del tricordio eólico es difuminado por la utilización de acordes con tercera, y no power chords. De esta forma, al oír los acordes completos (como Do\# menor, La mayor y Si mayor), la estructura armónica de este riff es leída dentro del modo mixolidio, y situada en el entorno de una tonalidad mayor ${ }^{19}$. Asimismo, la guitarra realiza un motivo sobre el acorde de Si que enlaza las notas Mi y Si con Re\# y Si que sugiere un breve giro IV-I (Mi mayor- Si mayor) que difumina la sonoridad del tricordio eólico.

Las estrofas de «Mil y una noches», aunque utilizan los mismos acordes que este riff y su motivo sobre Si, posicionan los acordes en diferente orden (esto es, La mayor - Si mayor - Do\# menor). Estos acordes están también realizados como acordes enteros y, por ello, las estrofas son oídas sobre un tricordio eólico en la tonalidad menor de Do \#. Esta tonalidad es la relativa del tono de la subtónica (VIIb) de Si (La Mayor), que cobra protagonismo a

19. El tricordio eólico en un modo menor con acordes completos estaría formado por dos acordes perfectos mayores y uno menor. Sin embargo, si el tricordio eólico se lee en una tonalidad mayor, estos acordes deberían ser dos perfectos menores y uno perfecto mayor. Los power chords, al eliminar la tercera, dejarían en suspenso estas relaciones propias de la armonía tonal clásica. 
través del giro VIIb-I que enlaza las estrofas y el estribillo, y en el que además se utiliza el power chord Si5. Por tanto, las estrofas que señalan el «tormento» amoroso del narrador utilizan de forma más evidente sonoridades del heavy (el tricordio eólico en menor, los power chords y el VIIb).

La salida de la atmósfera de tensión descrita en las estrofas se produce mediante la «romántica» declaración de compromiso del narrador en el estribillo («contigo viviré/ mil y una noches») cuya trascendencia estaría articulada sonoramente a través del giro al contexto mayor del riff principal. Esta estrategia se ve reforzada en los últimos estribillos, que presentan el tricordio eólico un semitono por encima en el modo mixolidio de Do. Do mayor es una de las tonalidades más usadas en la música tonal occidental, por lo que este giro contribuiría a reforzar la sensación de salida del ámbito menor y modal propio del heavy. Además, el paso a este estribillo final es el único momento de la canción en que Sangre Azul utiliza una sucesión de power chords (La5-Sol\#5-E5-Fa\#5-Si5), lo que amplifica este contraste.

La modulación uno o varios semitonos por encima es una característica que «Mil y una noches» comparte con «Livin' on a prayer» de Bon Jovi, y que Walser interpreta como un afianzamiento del discurso de trascendencia y poder del amor que rodeaba al tema (1993, p. 123). Como ilustra el caso de «Mil y una noches», Sangre Azul compartiría con Bon Jovi y con el glam metal el uso de maniobras sonoras que combinaban la fuerza y el poder del heavy con otras que se movían en una armonía más tonal y en un contexto de modalidad mayor asociado con el pop. Sin embargo, Walser apunta la existencia de estrategias de negociación entre el ámbito modal y menor, y el tonal y mayor en bandas clásicas de heavy americanas como Van Halen ${ }^{20}$. Esto significa que las estrategias usadas por Sangre Azul no eran sonoridades ajenas a la tradición del heavy, que, además, estaban lo suficientemente asentadas como para que Sangre Azul hubiera accedido a ellas ${ }^{21}$. En este sentido, la principal diferencia que tenía Sangre Azul con Barón Rojo era

20. Walser explica cómo Van Halen en su famoso riff de «Running with the devil» jugaba con la alternancia entre los power chords de Do5 y Re5, y el acorde completo de Mi Mayor. Así, aunque se utilizaba el tricordio eólico, su asociación con el modo menor quedaba desdibujada (1993, pp. 52-53).

21. El primer disco de Van Halen, de nombre homónimo y que contenía temas icónicos de la banda como el citado «Running with de devil», fue lanzado en 1978.

Feminismo/s 38, July 2021, 261-279 
el acudir a propuestas que venían no tanto del ámbito británico, sino del norteamericano, que había dado lugar a corrientes más abiertas en términos de género como el glam metal.

Estas influencias podían intuirse también a nivel iconográfico. Por ejemplo, la tipografía del primer disco de Sangre Azul, en azul metálico y con acabados en forma de triángulo, recordaba al usado por Van Halen en su álbum debut. Asimismo, al contrario que Barón Rojo, las portadas de Sangre Azul solían presentar fotografías de sus miembros. Éstos acostumbraban a aparecer llevando elaborados cardados de pelo, que en ocasiones teñían en tonos de rubio platino. También eran frecuentes en su vestuario complementos con estampados de leopardo y cazadoras llamativas (véase Ilustración 2).

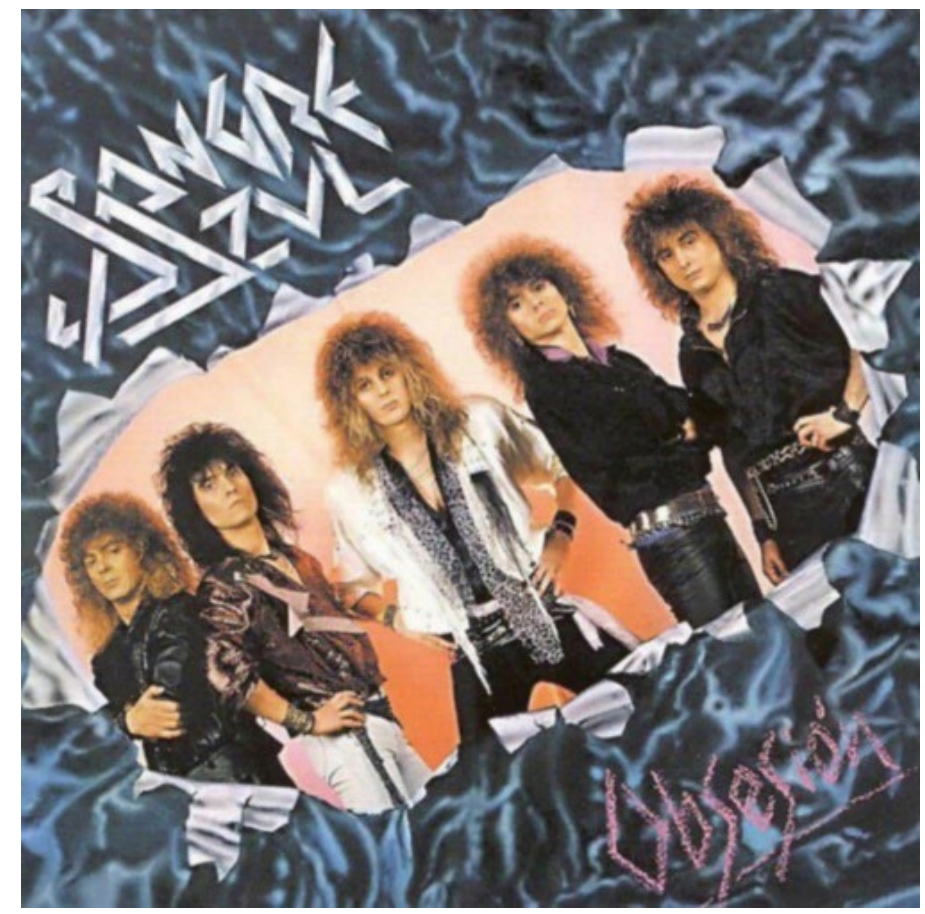

Ilustración 2. Portada del primer disco de Sangre Azul, Obsesión (1987), en la que se puede ver a los componentes del grupo con el pelo cardado y usando un vestuario que incluía estampados de leopardo típicos del glam o hair metal.

Feminismo/s 38, July 2021, 261-279 
De este modo, Sangre Azul ponía de manifiesto su preocupación por transmitir una imagen atractiva y «sexy», que estaba no sólo en el discurso visual del glam o hair metal, sino también en figuras como el cantante de Van Halen, David Lee Roth (Walser, 1993, p. 51). Esta estrategia podía suponer un problema para la articulación de una masculinidad heteronormativa, al posicionar al hombre en el rol de ser el objeto pasivo al que se admira, que tradicionalmente se ha asociado con las mujeres. Por tanto, quizá lo verdaderamente problemático para los fans del heavy español no era sólo el tipo de romanticismo de las letras de Sangre Azul, sino la conjunción entre éste y una imagen y unas estrategias visuales y musicales que eran disruptivas del discurso de masculinidad que asociaban con el heavy.

\section{CONCLUSIONES}

La contraposición del discurso de Barón Rojo con el de Sangre Azul permite reflexionar sobre las ansiedades que la articulación de una masculinidad heteronormativa producía dentro del heavy español y extranjero, y las formas de negociación del género que surgían en torno a él. Barón Rojo respondía con mayor fidelidad al discurso de masculinidad que articulaba el heavy anglosajón, y especialmente el británico. Sin embargo, el trabajo de Sangre Azul combinaba esta masculinidad más normativa con una vulnerabilidad romántica, especialmente evidente en las letras, propia de corrientes como el pop. En términos sonoros, esto suponía el uso de unas estructuras armónicas más tonales y mayores, y la utilización estratégica de elementos como los power chords. Sin embargo, este proceder estaba presente en gran parte del heavy americano de la época, no sólo en el glam o hair metal, caracterizado por la androginia, sino también en bandas canónicas como Van Halen. Por ello, aunque autores como del Val recogen que Sangre Azul fue menos aceptado por los fans tradicionales del heavy, cabe alegar que su trabajo estaba influenciado en igual medida que el de Barón Rojo por las propuestas «clásicas» del género.

El acercamiento a las corrientes norteamericanas del heavy pudo contribuir a que la audiencia de Sangre Azul tuviera un mayor número de mujeres, pero también es posible que fuera una dificultad para la legitimación del grupo. Esto pudo ser consecuencia, en parte, de que Sangre Azul no se 
ajustaba de forma ortodoxa a cuestiones relacionadas con la homosocialidad y la fraternidad masculina, que permean las escenas del heavy. Asimismo, cabe subrayar de nuevo que las diferencias entre Sangre Azul y Barón Rojo se aprecian no sólo en los textos y la iconografía, sino también en las propias estrategias sonoras. Por todo ello, el caso de Sangre Azul y Barón Rojo es un buen ejemplo de cómo la música ayuda a configurar diferentes discursos de género, y pone de manifiesto la importancia y el peso que la articulación de la masculinidad tiene dentro del heavy nacional y extranjero.

\section{REFERENCIAS BIBLIOGRÁFICAS}

Allué Montilla, I. (2017). Mujeres, rock y heavy metal: ¿quién dijo sexo débil? Milenio.

Clifford-Napoleone, A. R. (2015). Queerness in Heavy Metal Music: Metal Bent. Routledge.

Connell, R. W. (1995). Masculinities ( ${ }^{a}$ ed.) (2005). University of California Press.

Cope, A. L. (2010). Black Sabbath and the rise of heavy metal music. Ashgate.

del Val, F. (2017). Rockeros insurgentes, modernos complacientes: un análisis sociológico del rock en la Transición (1975-1985). Fundación SGAE.

Domínguez, S. (2004). Los hijos del rock: los grupos hispanos 1975-1989. Sociedad General de Autores.

Galicia Poblet, F. (2005). Espíritus rebeldes: el heavy metal en España. Fundación Autor/ SGAE.

García-Peinazo, D. (2019). Héroes frigios, nación y distorsión. La batalla por la supertónica descendida como signo musical en el metal español. Cuadernos de Música Iberoamericana, 32, 137-157. Recuperado de https:// doi.org/10.5209/cmib.65528

Giner, P. (mayo de 1987). Sangre Azul piden paso. Heavy Rock, 45, 6-7.

Heesch, F. (2019). «Voice of anarchy»: Gender aspects of aggressive metal vocals. The example of Angela Gossow (Arch Enemy). Criminocorpus. Rock et violences en Europe, Metal et violence (Febrero). Recuperado de: http://journals. openedition.org/criminocorpus/5726

Heesch, F., \& Scott, N. (Eds.). (2019). Heavy metal, gender, and sexuality. Routledge. 
Johnson, H. (2014). The interplay of authority, masculinity, and signification in the «grunge killed glam metal» narrative (Trabajo fin de máster). Recuperado de: https://doi.org/10.22215/etd/2014-10317

Lerena, V. (7 de febrero de 2018). Metallica se mete al público en el bolsillo con versiones de Obús y Barón Rojo y aún queda el Sant Jordi. 20 Minutos. Recuperado de: https://www.20minutos.es/noticia/3255047/0/metallica-mete-publico-bolsillo-versiones-obus-baron-rojo-queda-sant-jordi/

López Martínez, A. (2009). Cuerdas de acero: historia del heavy metal en España. Quarentena.

Martínez García, S. (2003). Decibelios y testosterona: una aproximación a las imágenes de género del rock y el heavy. Dossiers Feministes. No me arrepiento de nada: mujeres y música, 7, 101-118.

Martínez García, S. (2005). Monstruos y fronteras en el heavy: un análisis desde lo híbrido. Nassarre: Revista Aragonesa de Musicología, 21(1), 31-45.

Moore, S. (2011). Metal, Machismo and Musical Mode: How the 'Feminine' Phrygian Second has been Appropriated and Transformed. Networking Knowledge: Journal of the MeCCSA Postgraduate Network, 4(1), 1-26. Recuperado de https://doi.org/10.31165/nk.2011.41.67

Nordström, S., \& Herz, M. (2013). «It's a matter of eating or being eaten». Gender positioning and difference making in the heavy metal subculture. European Journal of Cultural Studies, 16(4), 453-467. Recuperado de https:// doi.org/10.1177/1367549413484305

Rogers, A. S. (2015). Women in Hypermasculine Environments: An Analysis of Gender Dynamics in the Heavy Metal Subculture.

Sangre Azul (n.d.). Discogs [página web]. Recuperado de: https://www.discogs. com/es/artist/2644955-Sangre-Azul

Sangre Azul (1988). Sangre Azul - Mini concierto (Programa A Tope 1988) [video].

Recuperado de: https://www.youtube.com/watch?v=Ix0EzM6kKUU

Sangre Azul. (2005). En Diccionario de Heavy Metal latino (p. 296). Sociedad General de Autores.

Sangre Azul (2011). ¿Por qué se separó Sangre Azul? [vídeo]. Recuperado de: https://www.youtube.com/watch?v=r7YNwJNDUek

Singla, J. (enero de 1988). Sangre Azul: A por su segundo álbum. Metal Hammer, 2, 20-21.

Walser, R. (1993). Running with the devil: power, gender, and madness in heavy metal music. University Press of New England. 
Weinstein, D. (2000). Heavy metal: the music and its culture. Da Capo.

Weinstein, D. (2009). The empowering masculinity in British heavy metal. En G. Bayer (Ed.), Heavy metal music in Britain (pp. 17-31). Ashgate. 